10. Клемешова К.В., Белоус О.Г. Сортовая диагностика функционального состояния Актинидии сладкой. - Germany: LAP Lambert Academic Publishing. - 2013. - 54 c. ISBN: 978-3-659-44008-3.

11. Олдендерфер М.С., Блэшфилд Р.К. Кластерный анализ. Факторный, дискриминантный и кластерный анализ / пер. с англ. под ред. И.С. Енюкова. - М.: Финансы и статистика. - 1989. - 215 с.

\title{
CLASSIFICATION OF ROSE (ROSA $\times$ HYBRIDA HORT.) CULTIVARS INTO GROUPS WITH DIFFERENT RESISTANCE USING THE CLUSTERING METHOD
}

\author{
Klemeshova K. V. ${ }^{2}$, Budarin A. A. ${ }^{1}$, Belous O. G. ${ }^{1}$ \\ ${ }^{I}$ Federal State Budgetary Scientific Institution \\ "Russian Research Institute of Floriculture and Subtropical Crops" \\ ${ }^{2}$ Resort area "Imeretinsky" \\ c. Sochi, Russia,e-mail: klemeshova_kv@mail.ru
}

The paper considers possible use of the clustering method to classify rose cultivars into groups (clusters) relatively uniform in terms of resistance according to their physiological and biochemical parameters. The authors detail the stages of statistical analysis. Considering the goal, cultivar groups were allocated according to their resistance: three (resistant, medium resistant and not resistant) or two (resistant and not resistant), a certain number of clusters can be specified -3 or 2 . As a result, it was found that with a large amount of the analyzed laboratory material it is possible to use clustering to speed up the process of classifying cultivars into groups and stimulate the processing of experimental data.

Key words: clustering, garden roses, cultivars, functional group, physiological parameters.

УДК 635.9:58.02

doi: $10.31360 / 2225-3068-2018-67-50-58$

\section{АНАЛИЗ КОЛЛЕКЦИИ \\ ТРОПИЧЕСКИХ И СУБТРОПИЧЕСКИХ ВИДОВ РАСТЕНИЙ \\ В ЗИМНЕМ САДУ ВНИИЦИСК В УСЛОВИЯХ НИЗКОЙ ОСВЕЩЁННОСТИ}

\author{
Козина Е. В., Яшмурзина Д. С. \\ Федеральное государственное бюджетное научное учреждение \\ «Всероссийский научно-исследовательский институт иветоводства и субтропических культур», \\ 2. Сочи, Россия, e-mail: cvetovodstvo@vniisubtrop.ru
}

Произведён анализ устойчивости коллекции тропических и субтропических растений, культивируемых в зимнем саду ВНИИЦиСК к условиям низкой освещённости. Коллекция состоит из 39 семейств, 70 родов и 120 видов растений (в том числе разновидностей и форм). Растения разделены на три группы по их 
Глава 2. Интродукция и сортоизучение

потребности к инсоляции: тенелюбивые, теневыносливые и светолюбивые. На основе ежедневных многолетних измерений с помощью люксметра построен график изменений интенсивности освещённости зимнего сада в течение года. Выделены виды, наиболее приспособленные к условиям низкой освещённости.

Ключевые слова: зимний сад, освещённость, анализ коллекции, адаптационный потенциал, устойчивость.

Зимний сад - источник красоты, гармонии и настроения. Этот зелёный оазис способен радовать глаз, восстанавливать душевный и физический комфорт и воспитывать чувство прекрасного. Кроме того, растения прекрасно очищают воздух от пыли и вредных примесей, насыщают его кислородом и увеличивают влажность воздуха в зимний период во время отопительного сезона, создавая благоприятный микроклимат $[1,2]$.

Зимний сад ВНИИЦиСК заложен на цокольном этаже трёхэтажного здания, построенного по примеру проектов сооружений, возводимых в жарких условиях среднеазиатского климата с высокой природной инсоляцией [10]. Особенностью этой архитектурной постройки являются крупномасштабные бетонные стены в виде решётки, выступающие на метр от стен здания и опоясывающие его со всех сторон. Такая конструкция способствует затенению окон и заметно снижает интенсивность солнечного излучения, что благоприятно влияет на микроклимат, создающийся в кабинетах, но снижает возможность выращивания растений внутри здания. В какой-то степени эту проблему решает наличие сплошного трёхстороннего остекления цокольного этажа, а также стеклянные квадратные проёмы на крыше здания, через которые происходит естественное освещение. Искусственных осветительных приборов в зимнем саду нет, что приводит к серьёзному недостатку света в течение всего года, однако, даже в этих условиях определённые виды растений способны выживать и сохранять свою декоративность.

Как известно, свет - один из основных лимитирующих факторов для существования растения, так как он необходим для протекания фотосинтеза, в результате которого образуются пластические вещества, идущие на его рост и развитие [11]. Его качество зависит от двух основных условий: длины светового дня, которая для нормальной вегетации растений не должна быть меньше 12-16 часов в день, и интенсивности освещения, потребность в которой зависит от вида растения. Нормы по интенсивности света для наиболее тенелюбивых видов составляют не менее 500 Лк зимой и до 3000 Лк - летом; для светолюбивых - не менее 3000 Лк зимой и до 10000 Лк летом [12]. 
Цель исследований. Цель данной работы - проанализировать устойчивость и декоративность тропических и субтропических культур коллекции зимнего сада ВНИИЦиСК в условиях низкой освещённости.

Объекты и методы исследований. Объектами исследований являются 39 семейств, 70 родов и 120 видов растений (разновидностей, форм), высаженных в условиях закрытого грунта ВНИИЦиСК [8]. Названия растений приведены согласно современной номенклатуры, в соответствии с электронным каталогом The plant list [13]. Измерение ocвещённости проводились с помощью цифрового люксометра AR813A, начиная с 2014 г. ежедневно с 12 до 14 часов.

Результаты исследований и их обсуждение. В результате проведённых многолетних измерений освещённости установлено, что среднегодовая интенсивность света в условиях зимнего сада института колеблется от 88 Лк в I декаде января до 1273 Лк в III декаде июня (рис. 1). Такая разница в показателях связана с тем, что в зимнее время обычно отмечается высокая облачность и частые дожди, в летнее время, так правило устанавливается сухая безоблачная погода, а кроме того это период приходится на летнее солнцестояние. При этом в отдельные годы значения могут опускаться до очень низких. Так в I декаде января 2018 г. был отмечен наименьший показатель - 15 Лк (табл. 1). Наибольший показатель был зафиксирован в III декаде июня 2017 г. - 2018 Лк.

Наблюдения показали, что большую часть года, точнее девять месяцев (с августа по апрель) отмечается довольно низкая освещённость - ниже 700 Лк. Условия Зимнего сада института являются неблагоприятными даже для выращивания многих видов тенелюбивых растений, но некоторые тропические и субтропические культуры демонстрируют поразительную жизнестойкость. Исходя из требований растений к освещенности, все когда-либо высаживаемые виды, были разбиты на три большие группы: тенелюбивые (предпочитают освещённость в диапазоне от 1000 до 3000 Лк), теневыносливые (освещённость в пределах от 3000 до 5000 Лк) и светолюбивые (освещённость от 5000 до 10000 Лк).

Самые тенелюбивые культуры в естественной среде растут в нижнем ярусе тропических и субтропических лесов в густой тени, поэтому могут эффективнее и легче других адаптироваться к недостаточному освещению. Наши многолетние наблюдения показали, что виды этой группы растений способны существовать в условиях зимнего сада института без заметного угнетения и, даже, успешно цвести, например: Aglaonema commutatum Schott и Aglaonema modestum Schott ex Engl., Chamaedorea elegans Mart. и Chamaedorea seifrizii Burret, Aspidistra elatior Blume. Также в эту группу входят папоротники, представленные родами Nephrolepis Schott., Adiantum L., Pteris L. и Asplenium L. [9, 3]. 


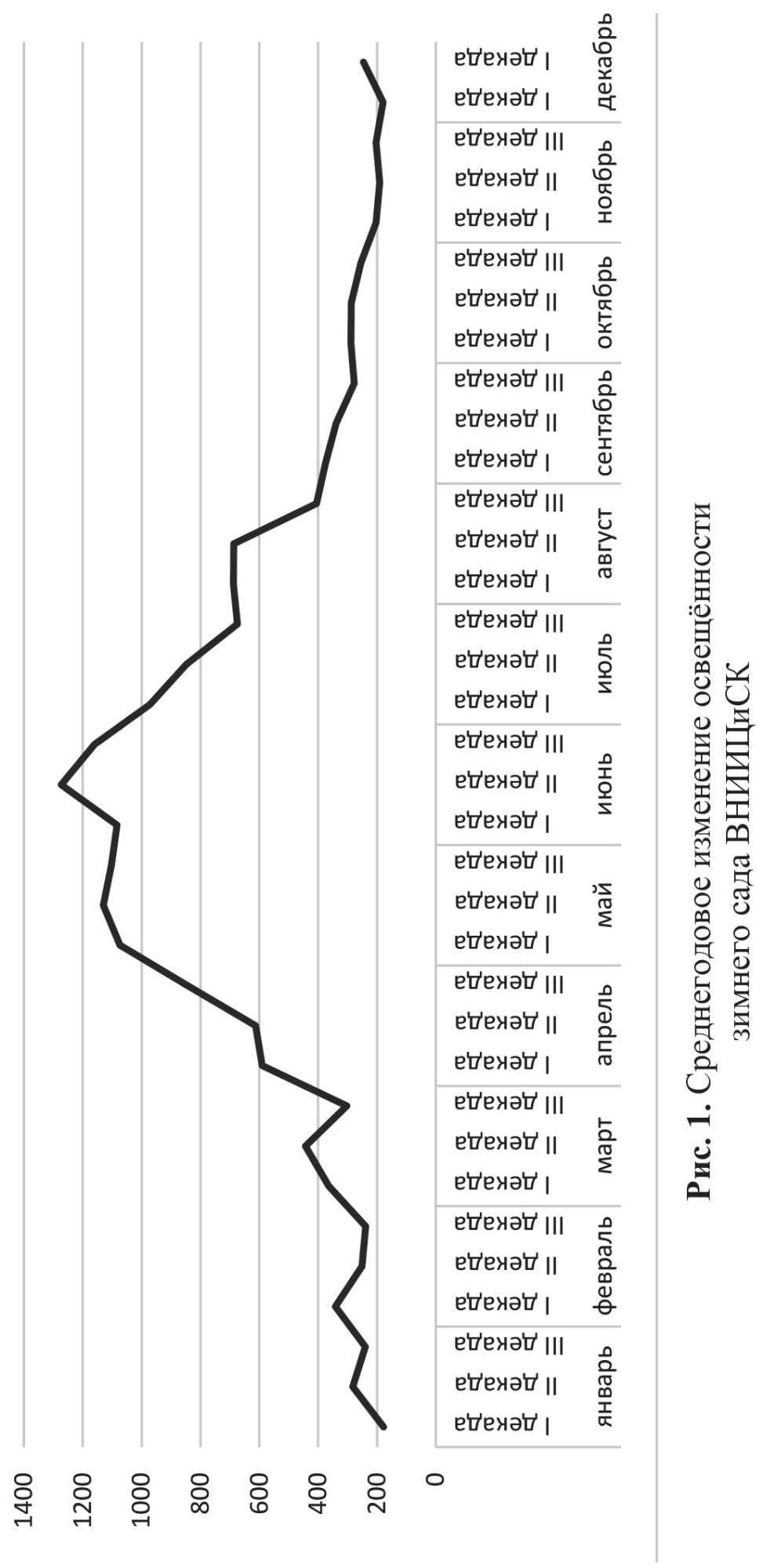


Субтропическое и декоративное садоводство (67)

Освещённость Зимнего сада ВНИИЦиСК

Таблий 1

в течение года в люксах, ЛК (2014-2018 гг.)

\begin{tabular}{|c|c|c|c|c|c|c|c|}
\hline \multirow{2}{*}{ Месяц } & \multirow{2}{*}{ Декада } & \multicolumn{5}{|c|}{ Год } & \multirow{2}{*}{ Средняя } \\
\hline & & 2014 & 2015 & 2016 & 2017 & 2018 & \\
\hline \multirow{3}{*}{ январь } & I декада & & & & 160 & 15 & 88 \\
\hline & II декада & & 171 & 200 & 210 & 129 & 178 \\
\hline & III декада & & 283 & 220 & 388 & 239 & 283 \\
\hline \multirow{3}{*}{ февраль } & I декада & & 234 & 283 & 216 & 227 & 240 \\
\hline & II декада & & 420 & 253 & 355 & 335 & 341 \\
\hline & III декада & & 244 & 190 & 178 & 394 & 252 \\
\hline \multirow{3}{*}{ март } & I декада & & 194 & 121 & 315 & 324 & 239 \\
\hline & II декада & & 366 & & 445 & 279 & 363 \\
\hline & III декада & & 549 & 319 & 453 & 451 & 443 \\
\hline \multirow{3}{*}{ апрель } & I декада & & 251 & 280 & 310 & 367 & 302 \\
\hline & II декада & & 714 & 241 & 550 & 854 & 590 \\
\hline & III декада & & 758 & 654 & 381 & 660 & 613 \\
\hline \multirow{3}{*}{ май } & I декада & & 1212 & 684 & 682 & 803 & 845 \\
\hline & II декада & 933 & 838 & 874 & 1572 & 1151 & 1074 \\
\hline & III декада & 903 & 1216 & 1327 & 745 & 1460 & 1130 \\
\hline \multirow{3}{*}{ июнь } & I декада & 934 & 1354 & 1409 & 313 & 1501 & 1102 \\
\hline & II декада & 831 & 1301 & 1447 & 1194 & 645 & 1084 \\
\hline & III декада & 866 & 868 & 1587 & 2018 & 1027 & 1273 \\
\hline \multirow{3}{*}{ июль } & I декада & 830 & 1074 & 885 & 1578 & 1433 & 1160 \\
\hline & II декада & 678 & 919 & 632 & 1398 & 1231 & 972 \\
\hline & III декада & 847 & 837 & 874 & 832 & & 848 \\
\hline \multirow{3}{*}{ август } & I декада & 650 & 484 & 779 & 786 & & 675 \\
\hline & II декада & 683 & 668 & 679 & 723 & & 688 \\
\hline & III декада & 490 & 751 & 821 & 683 & & 686 \\
\hline \multirow{3}{*}{ сентябрь } & I декада & 473 & 459 & 336 & 355 & & 406 \\
\hline & II декада & 298 & 411 & 483 & 309 & & 375 \\
\hline & III декада & 185 & 321 & 477 & 371 & & 339 \\
\hline \multirow{3}{*}{ октябрь } & I декада & 264 & 232 & 360 & 254 & & 278 \\
\hline & II декада & 213 & 326 & 379 & 238 & & 289 \\
\hline & III декада & 169 & 248 & 460 & 274 & & 288 \\
\hline \multirow{3}{*}{ ноябрь } & I декада & 289 & 237 & 174 & 320 & & 255 \\
\hline & II декада & 223 & 122 & 251 & 216 & & 203 \\
\hline & III декада & 221 & 148 & 154 & 242 & & 191 \\
\hline \multirow{3}{*}{ декабрь } & I декада & 179 & 144 & 264 & 224 & & 203 \\
\hline & I декада & 185 & 172 & 193 & 168 & & 180 \\
\hline & II декада & 213 & 272 & 270 & 228 & & 246 \\
\hline
\end{tabular}


Глава 2. Интродукция и сортоизучение

Следующая группа - теневыносливые растения - преимущественно представлена лианами, поднимающимися по стволам тропических зелёных великанов, и эпифитами, располагающимися на стволах деревьев. Это культуры среднего яруса леса, занимающие промежуточное положение в потребности солнечной инсоляции [4-6]. Их адаптационный потенциал ниже, чем у предыдущей группы, однако среди них есть виды, которые могут приспособиться к низкой круглогодичной освещённости. Например: Rhaphidophora decursiva (Roxb.) Schott, Spathiphyllum cochlearispathum (Liebm.) Engl., Spathiphyllum wallisii Regel, Howea belmoreana (C. Moore \& F. Muell.) Becc., Dracaena fragrans (L.) Ker Gawl., Billbergia nutans H. Wendl. ex Regel, Neoregelia spectabilis (T. Moore) L.B. Smith, Ficus benjamina L., Ficus binnendijkii Miq., Ficus elastic Roxb. ex Hornem.

Выживаемость других видов этой же группы во многом зависит от конкретного местоположения внутри зимнего сада и таких факторов как: близость к стеклянной стене, количество прямых солнечных лучей, падающих через стеклянные проёмы на крыше, затенение другими видами растений. Попадая в чуть более благоприятные условия эти виды растут, а иногда даже цветут. Если же место подобрано неудачно, то через некоторое время (обычно около полугода) они погибают. Это относится к следующим видам: Jacobinia carnea Lindl., Ruellia portellae Hook., Ruellia makoyana Hort. Makoy ex Closon, Eucharis grandiflora hort., Dieffenbachia maculata (Lodd.) Sweet, Monstera deliciosa Liebm., Scindapsus aureus (Linden \& André) Engl., Asparagus densiflorus (Kunth) Jessop, Asparagus plumosus Baker, Asparagus racemosus Willd., Dracaena marginata Hort., Ophiopogon japonicus (L.f.) Ker Gawl., Ophiopogon umbraticola Hance, Reineckea carnea (Andrews) Kunth, Rohdea japonica (Thunb.) Roth, Tillandsia concolor L.B. Sm., Cyperus alternifolius L., Persea americana Mill., Ficus pumila $\mathrm{L}$.

В группе теневыносливых растений есть такие, которые практически не приспосабливаются к условиям низкой освещённости и постепенно выпадают - это виды родов: Syngonium Schott., Tradescantia L., Sedum L., Peperomia Ruiz\&Pau.; а также Hypoestes sanguinolenta Hook., Monstera obliqua Mig., Philodendron erubescens K. Koch \& Augustin, Hedera helix L., Chlorophytum comosum (Thunb.) Jacques, Gynura aurantiaca (Blume) DC., Acalypha hispida Burm.f., Kohleria eriantha Hanst., Clerodendrum thomsoniae Balf.f., Pilea cadierei Gagnep. \& Guill. Для поддержания коллекции их приходится периодически досаживать.

Последняя группа, в которую входят самые светолюбивые культуры, в естественных условиях растущие, в большинстве своём, в саваннах, сухих каменистых тропиках и субтропиках [7]. У них самая высокая потребность в солнечном свете и, соответственно, самый низкий 
адаптивный потенциал к условиям зимнего сада. Следует отметить, что большинство видов этой группы посажены в модулях у стеклянной стены. Среди них тоже можно выделить виды наиболее хорошо себя чувствующие в данных условиях: Beaucarnea recurvata Lem., Aloe arborescens Mill., Cereus jamacaru DC., Marginatocereus marginatus (DC.) Backeb., Euphorbia leuconeura Boiss., Synadeniym grantii Hook f., Hibiscus rosa-sinensis L., Pandanus tectorius Parkinson ex Du Roi, Jasminum sambac (L.) Aiton Parkinson ex Du Roi. Эти виды достаточно хорошо вегетируют, не теряют свою декоративность, хотя и не цветут. Следующие виды этой группы замедленно растут и периодически выпадают в зимний период: Zamioculcas zamiifolia (Lodd. et al.) Engl., Sansevieria hyacinthoides (L.) Druce, Sansevieria trifasciata Prain, Austrocylindropuntia subulata (Muehlenpf.) Backeb., Myrtillocactus geometrizans (Mart. ex Pfeiff) Cons., Opuntia vulgaris Mill, Callisia fragrans (Lindl.) Woodson, Kalanchoe daigremontiana Raym.-Homet \& H. Perriet.

И, наконец, виды, которые не могут приспособиться к крайне низкому световому потоку и погибают в течение нескольких месяцев после посадки: все представленные виды родов Begonia L., Echinopsis Zucc., Epiphyllum Haw., Pelargonium L'Hér. ex Ait., и такие виды как Austrocylindropuntia salmiana (Parm. ex Pfeiff.) Backeb, Opuntia leucotricha DC., Stapelia asterias Masson, Cyanotis kewensis Clarke., Crassula arborescens (Mill.) Willd., Graptopetalum paraguayence (N.E.Br.) E. Walth., Alocasia macrorrhi$z o s$ (L.) G. Don. Последнюю группу растений высаживать не рекомендуется, так как они быстро теряют декоративность и требуют постоянной замены.

Заключение. Исследование состояния коллекции зимнего сада ВНИИЦиСК, находящейся в условиях чрезвычайно низкой освещённости позволило выделить виды растений, способных расти, оставаться декоративными и периодически цвести при сильной ограниченности инсоляции. Эти культуры можно смело рекомендовать для выращивания в закрытых помещениях со сходными условиями светового режима. Также в группах теневыносливых и светолюбивых растений были отмечены виды, способные, хоть и с заметным угнетением, существовать в подобных условиях. Их использование для озеленения при таких показателях света не даёт высокой гарантии выживаемости, однако они могут использоваться для расширения ассортимента культур в зимних садах при периодической подсадке и возобновлении. Третья выделенная группа - виды растений, не адаптирующиеся к данному освещению. Они рекомендуются для выращивания только в помещениях с более высокой инсоляцией. 


\title{
Библиографический список
}

1. Декоративные растения открытого и закрытого грунта / под ред. А.М. Гродзинского. - Киев: Наукова Думка, 1985. - 664 с.

2. Клемешова К.В., Келина А.В. Зимний сад ГНУ ВНИИЦиСК Россельхозакадемии // Научные исследования в субтропиках России: сб. трудов молодых учёных, аспирантов и соискателей. - Сочи: ВНИИЦиСК, 2013. - С. 201-209.- ISBN: 978-5-904-533-19-9.

3. Клемешова К.В. Принцы растительного мира // Цветоводство. - 2013. - № 2. C. 14-18. - ISSN: 0041-4905.

4. Клемешова К.В., Козина Е.В. Коллекция декоративно-лиственных видов в зимнем саду ВНИИЦиСК // Субтропическое и декоративное садоводство. - 2016. - Вып. 56. - C. 48-54. - ISSN: 2225-3068.

5. Клемешова К.В., Козина Е.В. Представители семейства Araceae Juss. в зимнем саду ВНИИЦиСК // Субтропическое и декоративное садоводство. - 2016. - Вып. 58. - С. 50 54. - ISSN: 2225-3068.

6. Клемешова К.В., Яшмурзина Д.С. Коллекция ампельных видов в зимнем саду ВНИИЦиСК // Субтропическое и декоративное садоводство. - 2017. - Вып. 61. С. 216-222. - ISSN: 2225-3068.

7. Клемешова К.В., Яшмурзина Д.С. Коллекция суккулетных растений в зимнем саду ВНИИЦиСК // Субтропическое и декоративное садоводство. - 2017. - Вып. 62. - С. 225-232. - ISSN: 2225-3068.

8. Клемешова К.В., Яшмурзина Д.С. Состояние коллекции тропических и субтропических видов в зимнем саду ВНИИЦиСК // Субтропическое и декоративное садоводство. - 2018. - Вып. 65. - С. 195-202 - doi: 10.31360/2225-3068-2018-65-195-202

9. Клемешова К.В., Яшмурзина Д.С. Стаффажные культуры в зимнем саду ВНИИЦиСК // Субтропическое и декоративное садоводство. - 2018. Вып. 64. - С. 190-197. - ISSN: 2225-3068.

10. Оболенский Н.В. Архитектура и солнце. - М.: Стройиздат, 1988. - 207 с.

11. Тимирязев К.А. Избранные работы по хлорофиллу и усвоению света растением. М.: Изд-во Академии Наук СССР, 1948. - 348 с.

12. Энциклопедия комнатного цветоводства / сост. Головкин Б.Н. - М.: Колос, 1993. - 343 с. 13. The plant list // A working list of all plant species [Electronic resource]. - URL: http:// www.theplantlist.org / (date of access: 26.09.2018).

\section{ANALYSIS OF THE COLLECTION OF TROPICAL AND SUBTROPICAL PLANT SPECIES IN THE WINTER GARDEN OF THE RUSSIAN RESEARCH INSTITUTE OF FLORICULTURE AND SUBTROPICAL CROPS IN LOW LIGHT CONDITIONS}

\author{
Kozina Ye. V., Yashmurzina D. S. \\ Federal State Budgetary Scientific Institution \\ "Russian Research Institute of Floriculture and Subtropical Crops", \\ c. Sochi, Russia, e-mail: cvetovodstvo@vniisubtrop.ru
}

The paper analyzed the resistance of tropical and subtropical plants cultivated in the winter garden of the Russian Research Institute of Floriculture and Subtropical Crops to low light conditions. The collection consists of 39 families, 70 genera and 
Субтропическое и декоративное садоводство (67)

120 plant species (including cultivars and forms). The plants are divided into three groups according to their need for insolation: shade-loving, shade-tolerant and light-loving. Based on daily multi-year measurements using a luxmeter, a graph of changes in the light intensity in the winter garden during a year was made. Species that are most adapted to low light conditions are identified.

Key words: winter garden, light intensity, collection analysis, adaptation potential, resistance.

\section{ПЕРСПЕКТИВЫ РАСШИРЕНИЯ \\ КУЛЬТИГЕННОГО АРЕАЛА ПРЕДСТАВИТЕЛЕЙ РОДОВ LIRIOPE LOUR. И OPHIOPOGON KER GAWL. ЗА ПРЕДЕЛАМИ СУБТРОПИЧЕСКОЙ ЗОНЫ РОССИИ}

Коннов Н. А.

Гойтхский филиал

Федерального государственного бюджетного научного учреждения «Всероссийский научно-исследовательский институт иветоводства и субтропических культур», c. Шаумян, Туапсинский район, Россия, e-mail: konnov_n_a@bk.ru

В работе даётся оценка перспективности культивирования представителей родов Liriope Lour. и Ophiopogon Ker Gawl. за пределами влажных субтропиков России. По результатам исследований установлена возможность их ограниченного использования в декоративном садоводстве центральных и северных районов Краснодарского края, выявлены отличия в сроках вегетации, предложен ряд агротехнических мероприятий по уходу за насаждениями. В качестве наиболее перспективных были выделены Liriope graminifolia, Ophiopogon japonicus, а также сорта O. Japonicas 'Pusillus' и O. Planiscapus 'Nigrescens', меньшая устойчивость которых компенсируется высокой декоративностью.

Ключевые слова: Liriope, Ophiopogon, декоративное садоводство, интродукция, газонообразующие растения.

Представители родов Liriope Lour. и Ophiopogon Ker Gawl. (сем. Convallariaceae) относятся к многолетним вечнозелёным злакоподобным растениям, получившим широкое распространение в декоративном садоводстве [5]. Благодаря высокой декоративности листьев, они преимущественно используются в качестве газонообразующих и бордюрных растений, а также фоновых элементов сложных ландшафтных экспозиций $[6,11]$. 